\title{
Degradabilidade ruminal da matéria seca de folhas e colmo de genótipos de Cynodon spp. em quatro idades de rebrota
}

\section{Ruminal degradability of dry matter of leaves and stem of genotypes of Cynodon spp. four ages of regrowth}

\author{
Euclides Reuter de Oliveira'; Flávio Pinto Monção ${ }^{2 *}$; Caroline Libonato Gordin ${ }^{3}$; \\ Andréa Maria de Araújo Gabriel ${ }^{1}$; Beatriz Lempp ${ }^{1}$; Mariana Viegas dos Santos ${ }^{4}$; \\ Sidnei Tavares dos Reis ${ }^{5}$; Lais Valenzuela Moura ${ }^{3}$
}

\begin{abstract}
Resumo
Objetivou-se avaliar a cinética ruminal de cinco genótipos do gênero Cynodon (Tifton 85, Jiggs, Russel, Tifton 68 e Vaqueiro), colhidos com idades de 28, 48, 63 e 79 dias com potencial para fenação. Para a degradabilidade in situ utilizaram três novilhos com cânulas ruminais, com tempos de incubação de 96, 72, 48, 12, 6 e 0 hora. Utilizou-se o delineamento em blocos casualizados em esquema de parcelas subdivididas (gramíneas como parcelas e idade ao corte como subparcelas) com três repetições. Houve redução $(\mathrm{P}<0,05)$ para os teores de fração prontamente solúvel (fração a), potencialmente degradável (fração b) e degradabilidade potencial da matéria seca da lâmina foliar e do colmo à medida que houve avanço no estádio de maturidade. Para degradabilidade potencial da matéria seca das folhas, constataram reduções diárias de 0,29; 0,47; 0,38; 0,39 e 0,26\% para Tifton 85, Jiggs, Russel, Tifton 68 e Vaqueiro, respectivamente. Recomenda-se o manejo de corte na idade de rebrota de 28 dias para fenação.
\end{abstract}

Palavras-chave: Composição bromatológica, degradação, forragem, ruminantes

\begin{abstract}
This study aimed to evaluate ruminal kinetics of five genotypes of Cynodon (Tifton 85, Jiggs, Russell, Tifton 68 and Vaqueiro), harvested, aged 28, 48, 63 and 79 days with potential for haymaking. For in situ was used three steers with rumen cannulae, with incubation times of 96, 72, 48, 12, 6 and 0 hours. We used a randomized block design in split plots (grass as plots and subplots as the cut time) with three replications. Decreased $(\mathrm{P}<0.05)$ to the levels of readily soluble fraction (fraction a), potentially degradable (fraction $b$ ) and the degradability of dry matter of the leaf and stem as there was increase in the maturity stage. For the degradability of dry matter of leaves, found daily reductions of 0.29 ; $0.47 ; 0.38 ; 0.39$ and $0.26 \%$ for Tifton 85 , Jiggs, Russell, Tifton 68 and Vaqueiro, respectively. It is recommended in the management of cutting regrowth age of 28 days from haymaking.
\end{abstract}

Key words: Bromatologic composition degradation, forage, ruminant

\footnotetext{
${ }^{1}$ Profs. Drs., Faculdade de Ciências Agrárias, Universidade Federal da Grande Dourados, UFGD, Dourados, MS. E-mail: euclidesoliveira@ufgd.edu.br; andrea.gabriel@ufgd.edu.br; beatrizlempp@ufgd.edu.br

${ }^{2}$ Discente do Curso de Doutorado em Zootecnia, Faculdade de Ciências Agrárias e Veterinária, Universidade Estadual Paulista "Júlio de Mesquita Filho", UNESP, Jaboticabal, SP. E-mail: moncaomoncao@yahoo.com.br

${ }^{3}$ Discentes do Curso de Mestrado em Zootecnia, UFGD, Dourados, MS. E-mail: valenzuelamoura@bol.com.br; carolinegordin@ hotmail.com

${ }^{4}$ Discente do Curso de Graduação em Zootecnia, UFGD, Dourados, MS. E-mail: mariana.viegas26@hotmail.com

${ }^{5}$ Prof. Dr., Dept ${ }^{\circ}$ de Ciências Agrárias, Universidade Estadual de Montes Claros, UNIMONTES, Campus Janaúba, Janaúba, MG. E-mail: sidnei.reis@unimontes.br

* Autor para correspondência
} 


\section{Introdução}

Os estudos sobre a cinética ruminal de forrageiras tropicais são importantes uma vez que, fornecem informações sobre as características nutritivas e concentração dos componentes das dietas além de proporcionar contribuição para novas tabelas de composição de alimentos (DELGADO; FRANZOLÍN NETO; GOMIDE, 2011).

A procura por forrageiras com potencial para elevada produção de biomassa (acima de 10.000 $\mathrm{kg}$ de MS ha-1 $\mathrm{ano}^{-1}$ ), associadas com bom valor nutricional (12\% de proteína Bruta, fibra com $60 \%$ degradável no rúmen) é pré-requisito para a maioria dos pecuaristas. Sendo assim, destaque é dado para alguns híbridos do gênero Cynodon que apresentam essas características, ou seja, rápido acúmulo de massa e grandes quantidades de matéria seca (MS), com boa relação lâmina foliar: colmo, resultando em forragem de bom valor nutritivo (GONÇALVES et al., 2002).

Como toda forrageira de clima tropical, estes genótipos concentram a maior parte de sua produção de biomassa durante o período das chuvas, consequência de fatores climáticos principalmente, como temperatura e precipitação pluviométrica (VAN SOEST, 1994). Desta forma, em algumas situações, adota-se a prática de conservar parte da produção de forragem do verão, para ser utilizada no inverno, com o intuito de manter uniforme a disponibilidade de volumoso para a alimentação animal durante todo o ano. Dentre as diversas formas de conservar a forragem, destaca-se a fenação. Entretanto, quando se trata da avaliação de forrageiras para confecção de fenos para os animais é importante o conhecimento do intervalo entre cortes que é um fator fundamental no manejo e que contribui para determinar a produção e a qualidade da forragem. Cortes a intervalos prolongados resultam em maior produção de massa seca, entretanto, promovem decréscimo acentuado sobre alguns nutrientes como a proteína bruta e os carboidratos solúveis. Segundo Van Soest (1994), a qualidade da forragem diminui com a maturação da planta, pelo aumento da lignificação da parede celular e pela diminuição da relação lâmina foliar: colmo e do teor de PB.

Esse aumento na lignificação restringe a atuação das enzimas digestivas produzidas pelos microrganismos do rúmen e, consequentemente, diminui a degradabilidade e a digestibilidade (WILKINS, 1969; PACIULLO et al., 2002). Esse decréscimo na degradabilidade pode ser explicado pelo acúmulo de colmos e material senescente e redução na proporção de lâminas foliares verdes, as quais apresentam a maior concentração de nutrientes digestíveis, neste sentido, é justificável o conhecimento da degradabilidade das lâminas foliares e colmos em diferentes idades de maturação (HERRERA; HERNANDEZ, 1989; OLIVEIRA et al., 2011). Com o decréscimo na qualidade do pasto, ocorre redução no consumo de nutrientes e, com isso, as necessidades de suplementação são aumentadas (AFRC, 1995). Velásquez et al. (2010) avaliaram genótipos do gênero Panicum, Brachiaria e Cynodon em diferentes idades de corte verificaram redução na degradabilidade e fração potencialmente degradável e aumento na espessura da parede celular na taxa de degradação.

O estudo da degradabilidade in situ dos alimentos por meio de uso de sacos de náilon incubados no rúmen não é recente (ORSKOV; MCDONALD, 1979). Trata-se de uma técnica que permite a avaliação simples e rápida da degradação do material contido nos sacos de náilon, em função do seu tempo de incubação, sendo usada por pesquisadores em ser mais uma alternativa para caracterização dos alimentos. Com base no exposto, objetivou-se determinar a degradação ruminal da matéria seca (MS) de gramíneas do gênero Cynodon, em quatro idades de corte com potencial para fenação.

\section{Material e Métodos}

O experimento foi realizado no período de abril de 2009 a setembro de 2010 nas dependências do setor de Zootecnia da Faculdade de Ciências 
Agrárias (FCA) na Universidade Federal da Grande Dourados (UFGD), localizada no município de Dourados - MS, onde a latitude é de $22^{\circ} 11^{\prime} \mathrm{S}$, longitude de $54^{\circ} 56^{\prime} \mathrm{W}$ e altitude de $450 \mathrm{~m}$, onde o solo é classificado como Latossolo Vermelho Distroférrico (EMBRAPA, 2006).
As forrageiras utilizadas (Jiggs, Russell, Tifton 68, Tifton 85 e Vaquero) foram amostradas em áreas já instalada no campo agrostológico da FCA. Conforme pode ser observado na tabela 1, o solo da área experimental apresentava as seguintes características químicas.

Tabela 1. Análise química do solo da área experimental em Dourados-MS.

\begin{tabular}{|c|c|c|c|c|c|c|c|c|c|c|}
\hline Profundidade & $\mathrm{pH} \mathrm{H} \mathrm{H}_{2} \mathrm{O}$ & $\mathrm{P}$ & $\mathrm{Ca}$ & $\mathrm{Mg}$ & $\mathrm{k}$ & $\mathrm{Al}$ & $\mathrm{H}+\mathrm{Al}$ & SB & $\mathrm{T}$ & $\mathrm{V}$ \\
\hline $\mathrm{cm}$ & \multicolumn{2}{|c|}{$\mathrm{m} \cdot \mathrm{g} / \mathrm{dm}^{3}$} & \multicolumn{7}{|c|}{----------------------------- CMol c------------------------ } & $\%$ \\
\hline $0-20$ & 5,7 & 2,0 & 3,7 & 0,2 & 0,17 & 0,24 & 5,0 & 9,31 & 9,2 & 45,5 \\
\hline
\end{tabular}

$\mathrm{pH}$ em água. $\mathrm{P}$ e K : extrator Mehlich ${ }^{-1} \cdot \mathrm{Ca}^{2+}, \mathrm{Mg}^{2+} \mathrm{e} \mathrm{Al}^{3+}$ : extrator $\mathrm{KCl}^{1} \mathrm{~mol} \mathrm{~L}^{-1} \cdot \mathrm{H}+\mathrm{Al}$ : extrator acetato de cálcio $0,5 \mathrm{~mol} \mathrm{~L}{ }^{-1}, \mathrm{pH}^{2}$ 7,0. SB: soma de bases. CTC (T): capacidade de troca catiônica a pH 7,0. V: índice de saturação de bases.

Fonte: Elaborados pelos autores.

Foi utilizado o delineamento em blocos ao acaso, com cinco tratamentos arranjados em um esquema de parcelas subdivididas, sendo os cinco genótipos estudados as parcelas e as quatro idades de corte as subparcelas $(28,48,63$ e 79 dias $)$.

A área experimental dos Cynodon spp utilizada foi dividida em quatro blocos totalizando $540 \mathrm{~m}^{2}$, sendo que cada parcela era de $9 \times 3 \mathrm{~m}$, totalizando $27 \mathrm{~m}^{2}$ por parcela e cada subparcela era de $2,25 \times 3 \mathrm{~m}$, totalizando $6,75 \mathrm{~m}^{2}$ com a área útil de $1 \mathrm{~m}^{2}$, localizada ao centro da subparcela.

Antes do início do experimento, no dia 16 de abril de 2009, realizou-se corte de uniformização a oito cm do solo, seguido de adubação de manutenção, que consistiu na aplicação do equivalente a $50 \mathrm{~kg} /$ ha de nitrogênio na forma de ureia (CANTARUTTI; ALVAREZ; RIBEIRO, 1999).

Os cortes das forragens foram efetuados em quatro datas pré-estabelecidas sendo estas 28 (13/05/09), 48 (02/06/09), 63 (17/06/09) e 79 (03/07/09) dias de rebrota, em uma área delimitada de $1 \times 1 \mathrm{~m}$ através do uso de um quadrado. As amostras coletadas foram separadas em lâminas foliares e colmo (colmo + bainha). Posteriormente, foram pré-secadas em estufa de ventilação forçada à $55^{\circ} \mathrm{C}$ por 72 horas.
O material foi moído com peneira de crivo de cinco mm de diâmetro. Parte das amostras foi novamente moídas em moinho dotado de peneira com crivo de um mm para determinação da matéria seca (MS) e proteína bruta $(\mathrm{PB})$, segundo metodologia descrita por Silva e Queiroz (2006). Para a determinação da fibra em detergente neutro (FDN) e fibra em detergente ácido (FDA) utilizou-se a metodologia sequencial descrita por Van Soest et al., (1991). O resíduo da FDA foi transferido para cadinho filtrante para a realização da análise de lignina "método de Klason” (SILVA; QUEIROZ, 2006).

Durante período experimental foram coletados dados de temperatura máxima ( $\mathrm{T}$ max), mínima ( $\mathrm{T}$ min) e média ( $\mathrm{T}$ md), umidade relativa média (UR $\mathrm{md}$ ) e precipitação (Prec) na estação meteorológica da UFGD, e os mesmos podem ser observados na tabela 2 .

Na tabela 3 podem ser observados os teores de matéria seca da lâmina (MSL), do colmo (MSC), proteína bruta da lâmina ( $\mathrm{PBL})$ e do colmo $(\mathrm{PBC})$, fibra em detergente neutro da lâmina (FDNL), do colmo (FDNC), fibra em detergente ácido da lâmina (FDAL), do colmo (FDAC), lignina da lâmina (LIGL) e do colmo (LIGC). 
Tabela 2. Dados sobre a Temperatura, Umidade Relativa e precipitação da região de Dourados-MS.

\begin{tabular}{|c|c|c|c|c|c|}
\hline \multirow{2}{*}{ DATA } & $\mathrm{T}^{\circ} \mathrm{MAX}$ & $\mathrm{T}^{\circ} \mathrm{MIN}$ & $\mathrm{T}^{\circ}$ Média & Umidade Relativa & Precipitação \\
\hline & \multicolumn{3}{|c|}{$\left({ }^{\circ} \mathrm{C}\right)$} & $(\%)$ & $(\mathrm{mm})$ \\
\hline $31 / 05 / 2009$ & 27,90 & 15,80 & 21,40 & 70,30 & 51,30 \\
\hline 30/06/2009 & 23,20 & 11,80 & 17,20 & 74,20 & 57,90 \\
\hline $31 / 07 / 2009$ & 22,75 & 13,90 & 17,42 & 79,21 & 152,10 \\
\hline $31 / 08 / 2009$ & 29,94 & 14,55 & 19,90 & 70,20 & 152,90 \\
\hline 30/09/2009 & 27,49 & 15,92 & 21,07 & 71,72 & 25,90 \\
\hline $31 / 10 / 2009$ & 30,21 & 18,41 & 23,61 & 73,12 & 301,50 \\
\hline
\end{tabular}

UFGD - Dados Meteorológicos, 2009.

Fonte: Elaboração dos autores.

Para a degradabilidade in situ foram utilizados três bovinos mestiços, machos, castrados, com idade de aproximadamente 38 meses e peso médio de $400 \mathrm{~kg}$, providos de cânula ruminal. Os animais foram alojados em um curral com água à vontade e alimentados com feno das mesmas gramíneas em estudo, sendo este administrado três vezes ao dia. Os animais passaram por um período de adaptação as dietas de 14 dias para em seguida se realizar as incubações.

Foi utilizada a técnica do saco de náilon, descrita por Mehrez e Orskov (1977), obedecendo-se às recomendações propostas por Nocek (1988) com modificação do material do saquinho utilizado $(5,0 \times 5,0 \mathrm{~cm})$, confeccionado utilizando-se tecido não- tecido (TNT - $100 \mathrm{~g} / \mathrm{m}^{2}$ ) (53 micras) segundo trabalho de Casali et al. (2008).

As amostras de cada idade e cultivar de Cynodon foram armazenados nos saquinhos na quantidade de $500 \mathrm{mg}$, obedecendo-se a relação de $10 \mathrm{mg}$ de $\mathrm{MS} / \mathrm{cm}^{2}$ de superfície segundo Nocek (1988). Os saquinhos foram colocados em uma sacola de filó de 15 x $30 \mathrm{~cm}$, juntamente com $100 \mathrm{~g}$ de peso de chumbo. As sacolas foram amarradas com um fio de náilon, deixando um comprimento livre de 1 metro para que as mesmas tivessem livre movimentação nas fases sólidas e líquidas do rúmen. As sacolas foram então depositadas na região ventral do rúmen por $96,72,48,36,12,6$ e 0 hora.

Após o período de incubação, as sacolas de filó foram tiradas do rúmen, abertas, e os saquinhos de TNT, contendo os resíduos da degradação, foram imediatamente colocados em balde com água gelada, para interromper a ação dos microorganismos. Em seguida foram lavados em água corrente e colocados em estufa a $55^{\circ} \mathrm{C}$ durante 72 horas.

Os saquinhos referentes ao tempo zero, para determinar a fração prontamente solúvel, foram introduzidos na massa ruminal e imediatamente retirados, recebendo, então, o mesmo procedimento destinado aos demais.

Os resíduos da degradabilidade foram analisados quanto ao teor de matéria seca (MS) segundo Silva e Queiroz (2006). Os procedimentos para a estimativa da degradabilidade da MS foram obtidos por diferença de peso encontrada para cada componente entre as pesagens, antes e após a incubação ruminal e expressos em porcentagem. De acordo com a diferença calculada entre o substrato e o resíduo, foram obtidos dados de desaparecimento da MS durante a incubação. 
Tabela 3. Composição bromatológica de cinco gramíneas do gênero Cynodon em quatro idades de rebrota.

\begin{tabular}{|c|c|c|c|c|c|c|}
\hline Variável & Idade de corte & Tifton 85 & Jiggs & Russell & Tifton 68 & Vaquero \\
\hline \multirow{4}{*}{ MSL } & 28 & 14,87 & 19,79 & 22,74 & 12,39 & 21,15 \\
\hline & 48 & 21,69 & 23,94 & 27,64 & 19,04 & 26,48 \\
\hline & 63 & 24,87 & 24,08 & 28,67 & 21,16 & 28,63 \\
\hline & 79 & 29,38 & 28,73 & 25,16 & 32,71 & 31,81 \\
\hline \multirow{4}{*}{ MSC } & 28 & 23,63 & 26,16 & 28,50 & 23,35 & 30,34 \\
\hline & 48 & 27,77 & 31,66 & 30,45 & 24,03 & 32,36 \\
\hline & 63 & 31,36 & 32,35 & 31,86 & 25,63 & 29,92 \\
\hline & 79 & 34,46 & 34,40 & 34,25 & 26,34 & 34,36 \\
\hline \multirow{4}{*}{ PBL } & 28 & 18,23 & 19,69 & 22,48 & 19,87 & 21,88 \\
\hline & 48 & 14,81 & 15,37 & 17,13 & 15,49 & 17,34 \\
\hline & 63 & 14,12 & 17,33 & 16,74 & 12,73 & 15,58 \\
\hline & 79 & 13,65 & 15,94 & 16,50 & 12,09 & 15,27 \\
\hline \multirow{4}{*}{$\mathrm{PBC}$} & 28 & 12,30 & 10,02 & 12,78 & 11,17 & 9,80 \\
\hline & 48 & 8,71 & 9,54 & 10,83 & 8,66 & 8,75 \\
\hline & 63 & 8,03 & 8,75 & 10,59 & 7,98 & 7,23 \\
\hline & 79 & 7,56 & 7,71 & 7,06 & 5,61 & 6,77 \\
\hline \multirow{4}{*}{ FDNL } & 28 & 72,16 & 69,72 & 75,45 & 65,86 & 77,61 \\
\hline & 48 & 74,36 & 78,59 & 76,55 & 72,61 & 79,41 \\
\hline & 63 & 74,55 & 58,61 & 76,24 & 72,56 & 80,74 \\
\hline & 79 & 77,57 & 78,84 & 79,76 & 69,98 & 81,16 \\
\hline \multirow{4}{*}{ FDNC } & 28 & 77,72 & 78,16 & 78,96 & 74,29 & 81,91 \\
\hline & 48 & 78,01 & 76,66 & 79,78 & 77,33 & 80,28 \\
\hline & 63 & 78,83 & 76,78 & 79,68 & 76,56 & 84,31 \\
\hline & 79 & 78,98 & 78,32 & 80,25 & 77,99 & 85,02 \\
\hline \multirow{4}{*}{ FDAL } & 28 & 29,72 & 35,22 & 31,88 & 23,65 & 30,59 \\
\hline & 48 & 34,24 & 31,27 & 34,02 & 29,66 & 31,90 \\
\hline & 63 & 34,72 & 23,45 & 34,89 & 29,83 & 33,78 \\
\hline & 79 & 34,99 & 45,20 & 34,89 & 29,92 & 32,91 \\
\hline \multirow{4}{*}{ FDAC } & 28 & 39,84 & 36,14 & 36,50 & 37,44 & 33,39 \\
\hline & 48 & 40,20 & 36,88 & 37,18 & 36,10 & 31,97 \\
\hline & 63 & 40,60 & 36,77 & 36,90 & 40,11 & 35,48 \\
\hline & 79 & 41,09 & 40,70 & 38,84 & 41,58 & 38,08 \\
\hline \multirow{4}{*}{ LIGL } & 28 & 6,10 & 5,60 & 6,60 & 5,50 & 6,80 \\
\hline & 48 & 6,40 & 7,8 & 7,00 & 5,70 & 7,90 \\
\hline & 63 & 6,70 & 9,10 & 7,20 & 6,00 & 9,30 \\
\hline & 79 & 7,90 & 9,2 & 7,30 & 7,30 & 9,40 \\
\hline \multirow{4}{*}{ LIGC } & 28 & 8,00 & 8,30 & 8,20 & 6,90 & 8,40 \\
\hline & 48 & 8,20 & 9,90 & 8,30 & 7,10 & 8,50 \\
\hline & 63 & 8,50 & 10,20 & 8,90 & 7,50 & 10,10 \\
\hline & 79 & 8,70 & 11,00 & 10,20 & 8,60 & 10,90 \\
\hline
\end{tabular}

Fonte: Elaboração dos autores.

Os dados obtidos foram ajustados para Newton, com auxílio do Sistema para Análises regressão não linear pelo método de Gauss- Estatísticas e Genéticas (SAEG) (GOMES, 
1992), conforme a equação proposta por Orskov e McDonald (1979).

Uma vez calculadas as constantes a, b e c estas foram aplicadas à equação proposta por Orskov e McDonald (1979).

A degradabilidade efetiva da MS foi estimada para cada cultivar, levando-se em conta as taxa de passagem de $5 \% / \mathrm{h}$, a qual pode ser atribuída ao nível de ingestão alimentar médio, respectivamente, segundo preconizado pelo AGRICULTURAL RESEARCH COUNCIL - ARC (1984).

Utilizou-se o delineamento em blocos casualizados em esquema de parcelas subdivididas (gramíneas como parcelas e idade ao corte como subparcelas) com três repetições.
As médias foram submetidas à análise de variância utilizando o programa SISVAR (FERREIRA, 2011), e quando significativas pelo teste de $\mathrm{F}$, as mesmas foram analisadas por meio de equações de regressão, sendo testado modelo linear, quadrático e cúbico para melhor ajuste.

\section{Resultados e Discussão}

Houve diferença significativa $(\mathrm{P}<0,05)$ entre os genótipos avaliados quanto aos teores de fração prontamente solúvel "fração a" da lâmina e do colmo. Houve interação significativa entre genótipos $\mathrm{x}$ idades de corte (Tabela 4), onde os maiores teores de fração "a" foram observados quando as plantas apresentaram menor idade de corte (28 dias).

Tabela 4. Valores encontrados para a fração prontamente solúvel "a” da massa seca (MS), dos diferentes genótipos e idades de corte.

\begin{tabular}{|c|c|c|c|c|c|c|}
\hline \multicolumn{7}{|c|}{ LÂMINA } \\
\hline \multicolumn{7}{|c|}{ Idade de Rebrota (dias) } \\
\hline Genótipos & 28 & 48 & 63 & 79 & Equação de Regressão & $\mathrm{R}^{2}$ \\
\hline Tifton 85 & 29,95 & 27,56 & 22,19 & 19,68 & $\hat{\mathrm{Y}}=36,462-0,213 \mathrm{X}(\mathrm{P}=0,0001)$ & 0,95 \\
\hline Jiggs & 33,18 & 27,73 & 23,75 & 19,15 & $\hat{\mathrm{Y}}=40,893-0,274 \mathrm{X}(\mathrm{P}=0,0004)$ & 0,99 \\
\hline Russel & 27,03 & 22,24 & 21,25 & 17,02 & $\hat{\mathrm{Y}}=32,010-0,185 \mathrm{X}(\mathrm{P}=0,0001)$ & 0,96 \\
\hline Tifton 68 & 33,93 & 26,94 & 24,31 & 21,43 & $\hat{\mathrm{Y}}=39,829-0,241 \mathrm{X}(\mathrm{P}=0,0003)$ & 0,96 \\
\hline Vaquero & 31,38 & 23,82 & 22,26 & 19,35 & $\hat{\mathrm{Y}}=36,630-0,228 \mathrm{X}(\mathrm{P}=0,0001)$ & 0,93 \\
\hline \multicolumn{7}{|c|}{ Coeficiente de variação $(\%)=6,72$} \\
\hline \multicolumn{7}{|c|}{ COLMO } \\
\hline Genótipos & 28 & 48 & 63 & 79 & Equação de Regressão & $\mathrm{R}^{2}$ \\
\hline Tifton 85 & 29,58 & 25,33 & 22,08 & 18,99 & $\hat{\mathrm{Y}}=35,363-0,2086 \mathrm{X}(\mathrm{P}=0,0001)$ & 0,99 \\
\hline Jiggs & 33,01 & 23,79 & 22,70 & 16,51 & $\hat{\mathrm{Y}}=40,616-0,3048 \mathrm{X}(\mathrm{P}=0,0001)$ & 0,94 \\
\hline Russel & 27,54 & 23,53 & 21,34 & 18,15 & $\hat{\mathrm{Y}}=32,513-0,1812 \mathrm{X}(\mathrm{P}=0,0001)$ & 0,99 \\
\hline Tifton 68 & 32,99 & 23,94 & 23,11 & 17,61 & $\hat{\mathrm{Y}}=39,873-0,2837 \mathrm{X}(\mathrm{P}=0,0001)$ & 0,93 \\
\hline Vaquero & 31,18 & 23,35 & 23,01 & 21,61 & $\hat{\mathrm{Y}}=34,519-0,1786 \mathrm{X}(\mathrm{P}=0,0001)$ & 0,80 \\
\hline \multicolumn{7}{|c|}{ Coeficiente de variação $(\%)=5,45$} \\
\hline
\end{tabular}

P: Probabilidade.

Fonte: Elaboração dos autores.

$\mathrm{O}$ avanço na idade de corte dos genótipos promoveu redução linear das frações "a", "b" "DP" e "DE" da MS da lâmina e do colmo, e não afetou a taxa de degradação da fração b da MS (c), e aumentou linearmente a fração indegradável (FI) da MS da lâmina e do colmo.

À medida que aumentou um dia sobre a idade de corte, houve redução $(\mathrm{P}<0,001)$ de $0,21,0,27$, 
$018,0,24$ e $0,22 \%$ da fração "a" da matéria seca da lâmina dos genótipos Tifton 85, Jiggs, Russel, Tifton 68 e Vaqueiro, respectivamente. As maiores reduções da fração "a" da lâmina com o avanço da idade de corte foram observadas sobre os genótipos Jiggs $(0,27 \%)$ e Tifton 68 (0,24\%). Isso ocorreu provavelmente devido ao estágio de crescimento da planta sobre a composição química, como pode ser observado na tabela 3, onde houve aumento no teor de matéria seca, fibra em detergente neutro, fibra em detergente ácido e lignina e reduziu o teor de proteína bruta com o aumento da idade.

A fração "a" compreende principalmente os carboidratos solúveis como o amido e os carboidratos monossacarídeos que estão presente no conteúdo celular. Entretanto, sabe-se que à medida que a planta envelhece, há aumento da parede celular e redução do conteúdo celular e conseqüentemente da fração solúvel (VAN SOEST, 1994), fato observado nesta pesquisa justificando os resultados observados na fração da lâmina e do colmo. As frações prontamente solúveis dos alimentos contribuem muito para a produção dos ácidos graxos voláteis no rúmen, sendo a principal fonte de energia para os ruminantes (SÁ et al., 2011). Nesta pesquisa, observa-se que de forma geral, tanto na lâmina quanto no colmo dos genótipos estudados, os teores de fração prontamente solúvel foram elevados (acima de 10\%) para gramíneas de ciclo fotossintético $\mathrm{C} 4$, permitindo destacar o potencial destes genótipos para pastejo e/ou fenação.

Para o colmo, houve redução linear $(\mathrm{P}<0,05)$ de $0,20,0,30,018,0,28$ e $0,17 \%$ para os genótipos Tifton 85, Jiggs, Russel, Tifton 68 e Vaqueiro, respectivamente. A expressão desses dados é esperada, visto que o aumento da idade da planta promove um espessamento dos tecidos de sustentação, como parede celular, associada ao processo de lignificação (JUNG; ALLEN, 1995), onde se encontra a fração "b", com diminuição proporcional de conteúdo celular constituído por parte representativa da fração "a" (VAN SOEST, 1994).
Houve decréscimos nos teores de fração "a" tanto da lâmina quanto do colmo à medida que aumentou a idade de corte, o que é justificável em função do aumento dos teores de MS e FDN (Tabela 3) que aumentaram com o avanço da maturidade fisiológica da planta (BLASER, 1982; WILSON, 1994), o que está próximo dos dados obtidos por Ferreira et al. (2005) que avaliaram a cinética da degradação ruminal de gramíneas do gênero Cynodon em diferentes idades ao corte, encontraram teores de fração solúvel "a"da planta inteira próximos de $21 \%$ aos 21 dias de idade para o genótipo Tifton 85 . Esses resultados são próximos aos obtidos neste experimento que foram de $29,95 \%$ para a lâmina e 29,59\% para o colmo aos 28 dias de idade para o mesmo genótipo. Pequenas oscilações nos resultados ocorrem provavelmente devido as condições edafoclimáticas.

Para os teores de fração insolúvel, mas potencialmente degradável "b" da MS da lâmina, houve decréscimo $(\mathrm{P}<0,05)$ à medida que aumentou a idade de corte. Os maiores valores (46,96 e 45,33\%) foram observados nos genótipos Jiggs e Tifton 68, respectivamente, na idade de 28 dias de idade de corte (Tabela 5). Houve efeito de interação $(\mathrm{P}<0,05)$ entre os genótipos $\mathrm{x}$ idade de corte. Os teores de fração " $b$ " da lâmina e do colmo reduziram linearmente com o aumento da idade. Houve redução diária na fração "b" da lâmina de 0,$07 ; 0,20 ; 0,19 ; 0,15$ e $0,03 \%$, respectivamente para o Tifton 85, Jiggs, Russel, Tifton 68 e Vaqueiro. A variação marginal da fração " $b$ " da lâmina foi 9,62; 23,73; 24,36; 16,86 e 4,54\% para o Tifton 85, Jiggs, Russel, Tifton 68 e Vaqueiro, respectivamente. Para a fração "b" do colmo as reduções diárias foram de 0,$04 ; 0,12 ; 0,21 ; 0,09$ e $0,09 \%$ e a variação marginal entre a maior e menor idade de rebrota foram de foram de 6,$00 ; 15,80$; 26,$59 ; 11,35$ e $11,38 \%$ para o Tifton 85 , Jiggs, Russel, Tifton 68 e Vaqueiro, respectivamente. O conhecimento da variação diária e/ou marginal é uma estratégia importante na decisão de manejo para corte ou pastejo, uma vez que, permite 
relacionar resultados de produção de massa, o que possibilita maior disponibilidade de forragem e ganho por área, com a degradação da fração fibrosa no rúmen. Neste sentido, o manejo do Tifton 85 , Tifton 68 e Vaqueiro pode ser feito em idade de rebrota maior (79 dias), em relação aos demais genótipos, possibilitando aumento na produção de massa seca, em função da menor variação marginal ou redução diária. A redução da fração " $b$ " dos genótipos avaliados pode estar relacionada com a velocidade de formação das ligações do tipo estér da lignina com a hemecelulose com incremento da idade de rebrota, o que desfavorece a degradação no rúmen (VAN SOEST, 1994).

Tabela 5. Valores encontrados para a fração potencialmente degradável "b" da massa seca (MS), dos diferentes genótipos e idades de corte.

\begin{tabular}{|c|c|c|c|c|c|c|}
\hline \multicolumn{7}{|c|}{ LÂMINA } \\
\hline \multicolumn{7}{|c|}{ Idade de Rebrota (dias) } \\
\hline Genótipos & 28 & 48 & 63 & 79 & Equação de Regressão & $\mathrm{R}^{2}$ \\
\hline Tifton 85 & 42,19 & 40,60 & 39,40 & 38,13 & $\hat{\mathrm{Y}}=44,420-0,0796 \mathrm{X}(\mathrm{P}=0,0001)$ & 0,98 \\
\hline Jiggs & 45,33 & 41,40 & 39,76 & 34,57 & $\hat{\mathrm{Y}}=51,243-0,2014 \mathrm{X}(\mathrm{P}=0,0001)$ & 0,96 \\
\hline Russel & 42,60 & 36,47 & 34,94 & 32,22 & $\hat{\mathrm{Y}}=47,310-0,1973 \mathrm{X}(\mathrm{P}=0,0001)$ & 0,95 \\
\hline Tifton 68 & 46,96 & 43,86 & 41,53 & 39,04 & $\hat{\mathrm{Y}}=51,311-0,1553 \mathrm{X}(\mathrm{P}=0,0001)$ & 0,99 \\
\hline Vaquero & 38,51 & 37,82 & 37,31 & 36,76 & $\hat{\mathrm{Y}}=39,469-0,0343 \mathrm{X}(\mathrm{P}=0,0001)$ & 0,99 \\
\hline \multicolumn{7}{|c|}{ Coeficiente de variação $(\%)=7,93$} \\
\hline \multicolumn{7}{|c|}{ COLMO } \\
\hline Genótipos & 28 & 48 & 63 & 79 & Equação de Regressão & $\mathrm{R}^{2}$ \\
\hline Tifton 85 & 40,46 & 39,50 & 38,78 & 38,03 & $\hat{\mathrm{Y}}=41,792-0,0477 \mathrm{X}(\mathrm{P}=0,0001)$ & 0,99 \\
\hline Jiggs & 40,06 & 39,27 & 36,04 & 33,73 & $\hat{\mathrm{Y}}=44,357-0,1299 \mathrm{X}(\mathrm{P}=0,0001)$ & 0,92 \\
\hline Russel & 39,55 & 36,07 & 31,91 & 29,03 & $\hat{\mathrm{Y}}=45,681-0,2118 \mathrm{X}(\mathrm{P}=0,0001)$ & 0,99 \\
\hline Tifton 68 & 41,56 & 39,71 & 38,31 & 36,84 & $\hat{\mathrm{Y}}=44,153-0,0926 \mathrm{X}(\mathrm{P}=0,0001)$ & 0,99 \\
\hline Vaquero & 37,42 & 35,75 & 33,23 & 33,16 & $\hat{\mathrm{Y}}=39,857-0,0911 \mathrm{X}(\mathrm{P}=0,0001)$ & 0,91 \\
\hline
\end{tabular}

P: Probabilidade.

Fonte: Elaboração dos autores.

Brito e Deschamps (2001), ao trabalharem com três cultivares de capim-elefante, verificaram que a área ocupada pelo tecido lignificado aumentou com o crescimento das plantas, tanto nas folhas quanto no colmo. O estágio de maturidade é importante fator a influenciar sobre o valor nutricional da planta forrageira e sobre a taxa de degradação da fração potencialmente degradável (fração b). Mesmo que seja perceptível o declínio na qualidade das lâminas e dos colmos com o avanço da idade, não ocorrem variações nas taxas de degradação dos tecidos ( $\mathrm{P}>0,05$ ) (Tabela 6), o que pode ser explicado em função da baixa contribuição relativa de cada tecido na folha e do colmo que segundo Wilson (1994), não se altera com a idade em estudo.

Houve diferença significativa $(\mathrm{P}<0,05)$ sobre a degradabilidade potencial (DP) da MS das folhas e do colmo dos genótipos estudados (Tabela 7). Houve efeito $(\mathrm{P}>0,05)$ de interação entre genótipo $\mathrm{x}$ idade de corte para a DP das folhas e do colmo. Assim como observado nas frações "a" e "b", verificou-se redução na DP da MS tanto da folha quanto do colmo, o que é justificável, uma vez que, a DP é a soma das frações prontamente solúveis (a) e insolúveis, mas potencialmente degradáveis (b). Nas folhas, constataram reduções diárias de 0,29; 0,$47 ; 0,38 ; 0,39$ e $0,26 \%$ para Tifton 85 , Jiggs, 
Russel, Tifton 68 e Vaqueiro, respectivamente. Para o colmo, verificaram reduções marginais entre a maior e menor idade de rebrota de 18,58; 31,68; 28,$76 ; 26,94$ e 20,50\% respectivamente para o Tifton 85, Jiggs, Russel, Tifton 68 e Vaqueiro. A variação de respostas dos diferentes genótipos a degradação ruminal provavelmente pode ser atribuída, principalmente, à natureza celulósica das paredes celulares presente nesses tecidos. De acordo com Engels e Schuurmans (1992), as paredes primárias, por apresentarem maior concentração de celulose, são mais prontamente digeríveis. Enquanto isso, as secundárias, normalmente mais espessas e com maior grau de lignificação e formação de ligação com a hemecelulose, o que tornam mais resistentes à ação microbiana.

Tabela 6. Valores encontrados para a taxa de degradação da fração b da massa seca (MS) em comparação entre os genótipos e as idades de corte.

\begin{tabular}{|c|c|c|c|c|}
\hline \multicolumn{5}{|c|}{ LÂMINA } \\
\hline \multicolumn{5}{|c|}{ Idade de Rebrota (dias) } \\
\hline Genótipos & 28 & 48 & 63 & 79 \\
\hline Tifton 85 & 0,056 & 0,049 & 0,042 & 0,041 \\
\hline Jiggs & 0,050 & 0,045 & 0,038 & 0,034 \\
\hline Russel & 0,042 & 0,047 & 0,044 & 0,041 \\
\hline Tifton 68 & 0,050 & 0,045 & 0,043 & 0,039 \\
\hline Vaquero & 0,057 & 0,051 & 0,043 & 0,043 \\
\hline \multicolumn{5}{|c|}{ Coeficiente de variação $(\%)=15,49$ (Probabilidade $>0,05)$} \\
\hline \multicolumn{5}{|c|}{ COLMO } \\
\hline Genótipos & 28 & 48 & 63 & 79 \\
\hline Tifton 85 & 0,058 & 0,056 & 0,051 & 0,049 \\
\hline Jiggs & 0,055 & 0,053 & 0,051 & 0,044 \\
\hline Russel & 0,041 & 0,040 & 0,04 & 0,039 \\
\hline Tifton 68 & 0,055 & 0,046 & 0,043 & 0,036 \\
\hline Vaquero & 0,048 & 0,048 & 0,046 & 0,046 \\
\hline
\end{tabular}

Coeficiente de variação $(\%)=22,96$ (Probabilidade $>0,05)$

P: Probabilidade.

Fonte: Elaboração dos autores.

Uma característica importante para a obtenção de feno de qualidade consiste na observação da relação lâmina foliar: colmo, devido a uma interação positiva entre consumo, degradabilidade e a porcentagem de folha no feno que é maior quando a forragem é colhida na idade ideal. Sendo assim, o aumento da idade da planta, promove uma redução da proporção lâmina foliar: colmo, em decorrência da intensificação do processo de alongamento dos colmos, que diferenciam quimicamente das folhas devido ao elevado teor de fibra em detergente neutro e menor teor de proteína (Tabela 3) e fósforo (VAN
SOEST, 1994), justificando o comportamento linear decrescente da DP e degradabilidade efetiva (DE) (Tabela 8) da MS observada nesta pesquisa. Assim, apesar da maior produção de matéria seca com o avanço da idade da planta, é conveniente o corte mais frequente (28 dias), ainda que isto resulte em menor produção por área (GOMIDE, 1980).

A degradabilidade ruminal da matéria seca, ou das diferentes frações que compõem a matéria, é um dos parâmetros em que a expressão da diversidade e os arranjos químicos da parede celular dos tecidos vegetais podem ser mais facilmente comprovados 
(DESCHAMPS, 1994), fato este observado nesta pesquisa, uma vez que, embora os genótipos é do mesmo gênero, o arranjo estrutural do dossel e celular apresentam diferenciações, o que permite obter alterações no perfil de degradação ruminal. Em expressão da qualidade nutricional do feno ou das forragens a ser fenada, a idade de corte constitui um parâmetro de extrema importância, em função da maior idade de corte implicar em maior proporção de colmos, o que dificulta o processo de desidratação da forrageira em função da espessura da parede celular, comprometendo a qualidade nutricional do alimento e do tempo de conservação dos fardos.

Tabela 7. Valores encontrados para a degradabilidade potencial (DP) da massa seca (MS) em comparação entre os genótipos e as idades de corte.

\begin{tabular}{|c|c|c|c|c|c|c|}
\hline \multicolumn{7}{|c|}{ LÂMINA } \\
\hline \multicolumn{7}{|c|}{ Idade de Rebrota (dias) } \\
\hline Genótipos & 28 & 48 & 63 & 79 & Equação de Regressão & $\mathrm{R}^{2}$ \\
\hline Tifton 85 & 72,14 & 68,16 & 61,59 & 57,82 & $\hat{\mathrm{Y}}=80,875-0,2926 \mathrm{X}(\mathrm{P}=0,0001)$ & 0,97 \\
\hline Jiggs & 78,51 & 69,13 & 63,51 & 53,73 & $\hat{\mathrm{Y}}=92,129-0,4754 \mathrm{X}(\mathrm{P}=0,0001)$ & 0,99 \\
\hline Russel & 69,63 & 58,71 & 56,18 & 49,25 & $\hat{\mathrm{Y}}=79,314-0,383 \mathrm{X}(\mathrm{P}=0,001)$ & 0,96 \\
\hline Tifton 68 & 80,89 & 70,79 & 65,84 & 60,47 & $\hat{\mathrm{Y}}=91,135-0,397 \mathrm{X}(\mathrm{P}=0,0001)$ & 0,98 \\
\hline Vaquero & 69,88 & 61,63 & 59,57 & 56,11 & $\hat{\mathrm{Y}}=76,081-0,2621 \mathrm{X}(\mathrm{P}=0,0001)$ & 0,94 \\
\hline \multicolumn{7}{|c|}{ Coeficiente de variação $(\%)=4,70$} \\
\hline \multicolumn{7}{|c|}{ COLMO } \\
\hline Genótipos & 28 & 48 & 63 & 79 & Equação de Regressão & $\mathrm{R}^{2}$ \\
\hline Tifton 85 & 70,04 & 64,83 & 60,87 & 57,02 & $\hat{\mathrm{Y}}=77,154-0,2562 \mathrm{X}$ & 0,99 \\
\hline Jiggs & 73,03 & 63,07 & 58,74 & 49,89 & $\hat{Y}=85,169-0,4401 X$ & 0,98 \\
\hline Russel & 67,09 & 59,60 & 53,25 & 47,79 & $\hat{Y}=77,771-0,3824 X$ & 0,99 \\
\hline Tifton 68 & 74,55 & 63,65 & 61,42 & 54,46 & $\hat{Y}=84,018-0,3761 X$ & 0,96 \\
\hline Vaquero & 68,60 & 59,10 & 56,24 & 54,77 & $\hat{Y}=74,375-0,2697 X$ & 0,88 \\
\hline \multicolumn{7}{|c|}{ Coeficiente de variação $(\%)=4,99$} \\
\hline
\end{tabular}

P: Probabilidade

Fonte: Elaboração dos autores.

A maior proporção de colmos com o incremento da idade de rebrota pode reduzir a taxa de degradação da fração "b", o que não foi verificado nesta pesquisa. Logo a redução na DE ocorreu em função da fração "a" e "b". Segundo Aroeira et al. (1996), a degradabilidade efetiva da matéria seca pode ser considerada como a energia digerida no rúmen. Portanto, o manejo de corte para fenação dos genótipos em estudo na idade de 28 dias, implica uma provável maximização da disponibilidade de energia para a microbiota ruminal.

No modelo experimental utilizado, a degradabilidade potencial representa a degradação ruminal máxima, enquanto a degradabilidade efetiva leva em consideração a taxa de passagem do alimento pelo trato gastrintestinal.

$\mathrm{O}$ aumento na idade de rebrota dos genótipos proporcionou incremento diários de 0,$29 ; 0,47 ; 0,38$; 0,39 e $0,26 \%$ sobre os teores da fração indegradável (FI) da MS das lâminas no rúmen (Tabela 9). A FI colabora sensivelmente para o efeito de repleção ruminal, devido à lignina ser um composto fenólico tóxico aos microrganismos ruminais, além de não ser disponível como fonte de energia para o crescimento microbiano (MARTINS-COSTA et al., 2008). Dessa forma, provavelmente, animais 
alimentados com genótipos do gênero Cynodon nas idades de 79 dias ou maiores, sofram efeito de repleção ruminal pela referida fração, e tenha, com

genótipos e as idades de corte. isso, limitação do consumo pelo efeito físico da digesta (VIEIRA et al., 1997).

Tabela 8. Valores encontrados para a degradabilidade efetiva (DE) da massa seca (MS) em comparação entre os

\begin{tabular}{|c|c|c|c|c|c|c|}
\hline \multicolumn{7}{|c|}{ LÂMINA } \\
\hline \multicolumn{7}{|c|}{ Idade de Rebrota (dias) } \\
\hline Genótipos & 28 & 48 & 63 & 79 & Equação de Regressão & $\mathrm{R}^{2}$ \\
\hline Tifton 85 & 52,20 & 47,52 & 40,18 & 36,82 & $\hat{\mathrm{Y}}=61,432-0,3166 \mathrm{X}(\mathrm{P}=0,0001)$ & 0,97 \\
\hline Jiggs & 55,77 & 47,30 & 40,87 & 33,03 & $\hat{\mathrm{Y}}=68,424-0,4437 \mathrm{X}(\mathrm{P}=0,0001)$ & 0,99 \\
\hline Russel & 46,55 & 39,93 & 37,57 & 31,55 & $\hat{\mathrm{Y}}=54,315-0,2829 \mathrm{X}(\mathrm{P}=0,0001)$ & 0,98 \\
\hline Tifton 68 & 57,40 & 47,66 & 43,40 & 38,43 & $\hat{Y}=66,740-0,3673 X(P=0,0001)$ & 0,98 \\
\hline Vaquero & 51,78 & 42,82 & 39,62 & 36,31 & $\hat{\mathrm{Y}}=58,945-0,2993 \mathrm{X}(\mathrm{P}=0,0001)$ & 0,95 \\
\hline \multicolumn{7}{|c|}{ Coeficiente de variação $(\%)=5,11$} \\
\hline \multicolumn{7}{|c|}{ COLMO } \\
\hline Genótipos & 28 & 48 & 63 & 79 & Equação de Regressão & $\mathrm{R}^{2}$ \\
\hline Tifton 85 & 51,34 & 46,21 & 41,27 & 37,76 & $\hat{\mathrm{Y}}=58,951-0,2717 \mathrm{X}(\mathrm{P}=0,0001)$ & 0,99 \\
\hline Jiggs & 54,05 & 43,99 & 40,88 & 32,05 & $\hat{\mathrm{Y}}=65,264-0,4132 \mathrm{X}(\mathrm{P}=0,0001)$ & 0,97 \\
\hline Russel & 45,19 & 38,15 & 35,10 & 31,42 & $\hat{\mathrm{Y}}=51,979-0,2663 \mathrm{X}(\mathrm{P}=0,0003)$ & 0,98 \\
\hline Tifton 68 & 54,81 & 42,96 & 40,77 & 33,14 & $\hat{\mathrm{Y}}=64,967-0,4045 \mathrm{X}(\mathrm{P}=0,0001)$ & 0,95 \\
\hline Vaquero & 49,51 & 40,81 & 38,59 & 37,49 & $\hat{\mathrm{Y}}=54,322-0,2334 \mathrm{X}(\mathrm{P}=0,0001)$ & 0,86 \\
\hline
\end{tabular}

P: Probabilidade

Fonte: Elaboração dos autores.

Tabela 9. Valores encontrados para a fração indegradável (FI) da massa seca (MS) em comparação entre os genótipos e as idades de corte.

\begin{tabular}{|c|c|c|c|c|c|c|}
\hline \multicolumn{7}{|c|}{ LÂMINA } \\
\hline \multicolumn{7}{|c|}{ Idade de Rebrota (dias) } \\
\hline Genótipos & 28 & 48 & 63 & 79 & Equação de Regressão & $\mathrm{R}^{2}$ \\
\hline Tifton 85 & 27,86 & 31,84 & 38,41 & 42,18 & $\hat{\mathrm{Y}}=19,125+0,2926 \mathrm{X}(\mathrm{P}=0,0001)$ & 0,97 \\
\hline Jiggs & 21,49 & 30,87 & 36,49 & 46,27 & $\hat{\mathrm{Y}}=7,870+0,4754 \mathrm{X}(\mathrm{P}=0,0004)$ & 0,99 \\
\hline Russel & 30,37 & 41,29 & 43,82 & 50,75 & $\hat{\mathrm{Y}}=20,686+0,3830 \mathrm{X}(\mathrm{P}=0,0001)$ & 0,96 \\
\hline Tifton 68 & 19,11 & 29,21 & 34,16 & 39,53 & $\hat{\mathrm{Y}}=8,865+0,3970 \mathrm{X}(\mathrm{P}=0,0001)$ & 0,98 \\
\hline Vaquero & 30,12 & 38,37 & 40,43 & 43,89 & $\hat{\mathrm{Y}}=23,919+0,2621 \mathrm{X}(\mathrm{P}=0,0002)$ & 0,94 \\
\hline \multicolumn{7}{|c|}{ Coeficiente de variação $(\%)=8,4$} \\
\hline \multicolumn{7}{|c|}{ COLMO } \\
\hline Genótipos & 28 & 48 & 63 & 79 & Equação de Regressão & $\mathrm{R}^{2}$ \\
\hline Tifton 85 & 29,96 & 35,17 & 39,13 & 42,98 & $\hat{\mathrm{Y}}=22,846+0,2562 \mathrm{X}(\mathrm{P}=0,0001)$ & 0,99 \\
\hline Jiggs & 26,93 & 36,93 & 41,26 & 50,11 & $\hat{\mathrm{Y}}=14,780+0,4409 \mathrm{X}(\mathrm{P}=0,0005)$ & 0,98 \\
\hline Russel & 32,91 & 40,40 & 46,75 & 52,21 & $\hat{\mathrm{Y}}=22,229+0,3824 \mathrm{X}(\mathrm{P}=0,0001)$ & 0,99 \\
\hline Tifton 68 & 25,45 & 36,35 & 38,57 & 45,54 & $\hat{\mathrm{Y}}=15,982+0,3761 \mathrm{X}(\mathrm{P}=0,0001)$ & 0,96 \\
\hline Vaquero & 31,40 & 40,90 & 43,76 & 45,23 & $\hat{\mathrm{Y}}=25,625+0,2697 \mathrm{X}(\mathrm{P}=0,0001)$ & 0,88 \\
\hline
\end{tabular}

P: Probabilidade

Fonte: Elaboração dos autores. 


\section{Conclusão}

Os genótipos pertencentes ao gênero Cynodon analisados possui potencial para produção de feno de qualidade. Recomenda-se o manejo de corte na idade de rebrota de 28 dias.

\section{Agradecimentos}

Ao Conselho Nacional de Desenvolvimento Científico e Tecnológico e a Universidade Federal da Grande Dourados pelo apoio financeiro e pelas bolsas concedidas.

O artigo foi aprovado pela comissão de bioética e foi realizado de acordo com as normas técnicas de biossegurança e ética.

\section{Referências}

AGRICULTURAL RESEARCH COUNCIL - ARC. The nutrient requirements of ruminant livestock. Report of the protein group of the agricultural research council working party on the nutrient requirements of ruminants. 1984. 45 p. Supplement 1.

AGRICULTURALAND FOOD RESEARCH COUNCIL - AFRC. Energy and protein requirements of ruminants. CAB International, 1995.

AROEIRA, L. J. M.; LOPEZ, F. C. F.; DAYRELL, M. S. Degradabilidade de alguns alimentos no rúmen de vacas holandês/ zebu. Revista Brasileira de Zootecnia, Viçosa, MG, v. 25, n. 6, p. 1178-1186, 1996.

BLASER, R. E. Integrated pasture and animal management. Tropical Grasslands, Camberra, v. 16, n. 1, p. 9-24, 1982.

BRITO, C. J. F. A.; DESCHAMPS, F. C. Caracterização anatômica em diferentes frações de cultivares de Capimelefante (Pennisetum purpureum Schumach.). Revista Brasileira de Zootecnia, Viçosa, MG, v. 30, n. 1, p. 14091417, 2001.

CANTARUTTI, R. B.; ALVAREZ, V. V. H.; RIBEIRO, A. C. Pastagens. In: RIBEIRO, A. C.; GUIMARÃES, P. T. G.; ALVAREZ, V. V. H. (Ed.). Recomendações para uso de corretivos e fertilizantes em Minas Gerais: $5^{\text {a }}$ aproximação. Viçosa, MG: CFSEMG/UFV, 1999. p. 332-341.

CASALI, A. O.; DETMANN, E.; VALADARES FILHO,
S. C.; PEREIRA, J. C.; HENRIQUES, L. T.; FREITAS, S. G.; PAULINO, M. F. Influência do tempo de incubação e do tamanho de partículas sobre os teores de compostos indigestíveis em alimentos e fezes bovinas obtidos por procedimentos in situ. Revista Brasileira de Zootecnia, Viçosa, MG, v. 37, n. 2, p. 335-342, 2008.

DELGADO, D. C.; FRANZOLÍN NETO, R.; GOMIDE, C. A. Effect of non-degradable protein level in rumen on the in situ ruminal degradation of Bermuda grass (Cynodon dactylon (L.) Pers) cv. Coast-cross in buffaloes. Cuban Journal of Agricultural Science, Havana, v. 45, n. 2, p. 135-139, 2011.

DESCHAMPS, F. C. Degradabilidade ruminal da matéria seca e da proteína de alguns alimentos utilizáveis na alimentação de ruminantes. Revista Brasileira de Zootecnia, Viçosa, MG, v. 23, n. 6, p. 898-908, 1994.

EMPRESA BRASILEIRA DE PESQUISA AGROPECUÁRIA - EMBRAPA. Centro Nacional de Pesquisa de Solos. Sistema Brasileiro de Classificação dos Solos. Brasília: Embrapa STI, 2006. 412 p.

ENGELS, F. M.; SCHUURMANS, J. L. L. Relationship between structural development of cell walls and degradation of tissues in maize stems. Journal of Science and Food Agriculture, Kansas, v. 59, n. 1, p. 45-51, 1992.

FERREIRA, D. F. SISVAR: a computer statistical analysis system. Ciência e Agrotecnologia, Lavras, v. 35, n. 6, p. 1039-1042, 2011.

FERREIRA, G. D. G.; SANTOS, G. T.; CECATO, U.; CARDOSO, E. C. Composição química e cinética da degradação ruminal de gramíneas do gênero Cynodon em diferentes idades ao corte. Acta Scientiarum. Animal Sciences, Maringá, v. 27, n. 2, p. 189-197, 2005.

GOMES, J. M. SAEG 5.0: sistema de análises estatísticas e genéticas, SAEG. Viçosa: Imprensa Universitária, UFV, 1992. $100 \mathrm{p}$.

GOMIDE, J. A. Características de planta forrageira a ser fenada. Informe Agropecuário, Belo Horizonte, v. 6, n. 64, p. 6-8, 1980.

GONÇALVES, G. D.; SANTOS, G. T.; CECATO, U.; JOBIM, C. C.; DAMASCENO, J. C.; BRANCO, A. F.; FARIA, K. P. Produção e valor nutritivo de gramíneas do gênero Cynodon em diferentes idades ao corte durante o ano. Acta Scientiarum. Animal Sciences, Maringá, v. 24, n. 4, p. 1163-1174, 2002.

HERRERA, R. S.; HERNANDEZ, Y. Efecto de la edad de rebrote em alguns indicadores de la calidad de la bermuda cruzada - 1. III. Porcetaje de hojas y rendimientos de matéria seca y proteína bruta. Pastos y Forrajes, Matanzais, v. 12, n. 77, p. 77-81, 1989. 
JUNG, H. G.; ALLEN, M. S. Characteristics of plant cell walls affecting intake and digestibility of forages by ruminants. Journal of Animal Science, Champainge, v. 73, n. 1, p. 2774-2790, 1995.

MARTINS-COSTA, R. H. A.; CABRAL, L. S.; BHERING, M.; ABREU, J. G.; ZERVOUDAKIS, J. T.; RODRIGUES, R. C.; OLIVEIRA, I. S. Valor nutritivo do capim-elefante obtido em diferentes idades de corte. Revista Brasileira de Saúde e Produção Animal, Salvador, v. 9, n. 3, p. 397-406, 2008.

MEHREZ, A. Z.; ORSKOV, E. R. A study of the artificial fiber bag technique for determination the digestibility of feeds in the rumen. Journal of Agricultural Science, Cambridge, v. 88, n. 1, p. 645, 1977.

NOCEK, J. E. In situ and others methods to estimate ruminal protein and energy digestibility: A review. Journal of Dairy Science, Madison, v. 71, n. 8, p. 20512059, 1988.

OLIVEIRA, E. C. A.; FREIRE, F. J.; OLIVEIRA, R. I.; OLIVEIRA, A. C.; FREIRE, M. B. G. S. Acúmulo e alocação de nutrientes em cana-de-açúcar. Revista Ciência Agronômica, Fortaleza, v. 42, n. 3, p. 579-588, 2011.

ORSKOV, E. R.; McDONALD, I. The estimation of protein degradability in the rumen from incubation measurements weighted according to rate of passage. Journal of Agriculture Science, Cambridge, v. 92, n. 2, p. 449-453, 1979.

PACIULLO, D. S. C.; GOMIDE, J. A.; SILVA, E. A. M.; QUEIROZ, D. S.; GOMIDE, C. A. Degradação in vitro de tecidos da lâmina foliar e do colmo de gramíneas forrageiras tropicais, em função do estádio de desenvolvimento. Revista Brasileira de Zootecnia, Viçosa, MG, v. 31, n. 2, p. 900-907, 2002.
SÁ, J. F.; PEDREIRA, M. S.; SILVA, F. F.; FIGUEIREDO, M. P. F.; REBOUÇAS, M. N.; SOUZA, D. R. Cinética da fermentação in vitro do capim-Marandu em diferentes idades de corte. Acta Scientiarum. Animal Sciences, Maringá, v. 33, n. 3, p. 225-231, 2011.

SILVA, D. J.; QUEIROZ, A. C. Análise de alimentos: métodos químicos e biológicos. Viçosa: UFV, 2006. 235 p.

VAN SOEST, P. J. Nutritional ecology of the ruminant. London: Constock Publishing Associates, 1994. 476 p.

VAN SOEST, P. J.; ROBERTSON, J. B.; LEWIS, B. A. Methods for dietary fiber, neutral detergent fiber, and nonstarch polysaccharides in relation to animal nutrition. Journal of Dairy Science, Madison, v. 74, n. 10, p. 35833597, 1991.

VELÁSQUEZ, P. A. T.; BERCHIELLI, T. T.; REIS, R. A.; RIVERA, A. R.; DIAN, P. H. M.; TEIXEIRA, I. A. M. A. Composição química, fracionamento de carboidratos e proteínas e digestibilidade in vitro de forrageiras tropicais em diferentes idades de corte. Revista Brasileira de Zootecnia, Viçosa, MG, v. 39, n. 6, p. 1206-1213, 2010.

VIEIRA, R. A. M.; PEREIRA, J. C.; MALAFAIA, P. A. M.; QUEIROZ, A. C. The influence of the elephant-grass (Pennisetum purpureum Schum. Mineiro Variety) growth on nutrient kinetics in the rumen. Animal Feed Science and Technology, Toronto, v. 67, n. 2, p. 151-161, 1997.

WILKINS, R. J. The potencial digestibility of cellulose in forage and faeces. Journal Agricultural Science, Cambridge, v. 73, n. 1, p. 57-64, 1969.

WILSON, J. R. Cell wall characteristics in relation to forage digestion by ruminants. Journal of Agricultural Science, Cambridge, v. 122, n. 2, p. 173-182, 1994. 
